Jolobe; 'The Problems of the Author' by Professor C. L. S. Nyembezi; a paper on this subject was also read by Dr. H. J. van Zyl; 'The Manuscript' by Dr. C. J. Oosthuizen; 'Types of Manuscripts' by Professor D. Ziervogel; 'The Book Publisher' by G. F. Laurence. Mr. J. Semmelink, the founder and director of Informo (a Christian literature service for Southern Africa), also gave a paper on the need for a comprehensive catalogue of all publications in the Bantu languages of Southern Africa. Mr. Semmelink is compiling such a catalogue himself and has already listed more than 800 publications.

Among the problems facing the African author are illiteracy, the large number of African languages, and the problem of finding publishers. Points for the future on which resolutions were passed included the completion of the catalogue of Bantu publications mentioned above, the possible establishment of a Bantu Academy to consider matters of orthography and vocabulary in the field of Bantu languages, and the establishment of a Bureau of Literacy and Literature to combat illiteracy among the adult Africans of the Union and to ensure the more effective distribution of wholesome literature among the Africans of Southern Africa.

\title{
Tropical Africa Study Project
}

THE recently established Institute of Race Relations (6 Duke of York St., London, S.W. I) is undertaking a study of the human problems arising from the impact of industrialization in Africa, with special reference to the immediate context of industrial and commercial activity. The Study is under the direction of Mr. Guy Hunter, who left for Africa at the end of 1959 .

The growth of modern industry and commerce has coincided with major political changes in Africa, where the situation is complicated not only by the presence of several races but by their changing relationships. The object of the present Study is to assess how far the necessary adaptations in these relationships are being made successfully, particularly in the sphere of industry and commerce, by Governments, by social groups, by industrial undertakings, and by individuals in the actual context of work, and, if possible, to suggest means by which relationships can be improved. It is intended that the Study should include work in East, West, and Central Africa, and comparative material from countries with French and Belgian associations will be valuable. While in some cases there may be need for original research on special issues, the principal task will be to draw upon the widely varied experience of all races in Africa and to bring together that experience from different areas and from different viewpoints. It is intended that the results of the Study should be published.

\section{Economic Problems in Senegal}

M. IGOR De GARINE WIChatitsky, who has recently completed a field study of the Massa peoples as a Research Fellow of the International African Institute, has been engaged by the Food and Agricultural Organization of the United Nations to make a four-month study of food and economic problems in Senegal.

\section{Research among the Konso of Ethiopia}

Mr. Richard KLUCKhohn, working under the supervision of Professor John W. M. Whiting, Director of the Laboratory of Human Relations, Harvard University, and supported by a grant from the National Institute of Mental Health, is doing a general ethnographic field survey of the Konso, with particular emphasis on child training, age grading, 